\title{
The Entrapment of Dorsal Nerve of Penis/Clitoris Under the Pubis: An Alternative Source of Pudenal Neuralgia
}

\section{TO THE EDITOR:}

The article of Peng and Tumber (1) nicely reviewed current knowledge about ultrasound-guided interventional procedures for patients with piriformis syndrome, border nerve syndrome, and pudendal neuralgia. In the case of pudendal neuralgia, they stated that pudendal nerve entrapment syndrome might be caused either by the pudendal nerve entrapment between the sacrotuberous and the sacrospinous ligament or inside the Alcock's canal (1). However, current research of this topic showed there is another possible site of pudendal nerve entrapment - the compression of the dorsal nerve of the penis/clitoris against the lower border of the pubic bone, where the nerve runs in a close proximity to the bone, in the sulcus nervi dorsalis penis/clitoridis (2-6). The nerve entrapment in this site might mimic the clinical picture of the 2 above mentioned "typical" types of pudendal nerve entrapment syndromes and thus cause a diagnostic challenge (7). Although the first report of this syndrome comes from 1981 (8) and from that time this syndrome has been extensively studied, some aspects are still not known. Most importantly, no diagnostic algorithm to distinguish between particular types of pudendal nerve entrapment syndromes has been developed yet. I believe ultrasound might be very helpful in differential diagnosis of dorsal nerve entrapment in the future. Possibly, it might be helpful in evaluation of the degree of fibroplasia around the nerve. An ultrasound-guided dorsal nerve block might also be helpful to distinguish between entrapments of the dorsal nerve of the penis/clitoris and pudendal nerve trunk. Moreover, it might be also helpful in treatment of dorsal nerve syndrome.

Jiri Šedý, MD

Institute of Experimental Medicine

Academy of Sciences of the Czech Republic

Videnskia, 1083

142 20, Prague 4

Czech Republic

E-mail: jirisedy@hotmail.com

\section{References}

1. Peng PWH, Tumber PS. Ultrasoundguided interventional procedures for patients with chronic pelvic pain - a description of techniques and review of literature. Pain Physician 2008; 11:215224.

2. Sedy J, Nanka O, Walro JM, Belisová M, Jarolím L. Sulcus nervi dorsalis penis/ clitoridis: Anatomic structure and clinical significance. Eur Urol 2006; 50:10791085.

3. Hruby S, Ebmer J, Dellon L, Aszmann OC. Anatomy of pudendal nerve at uro- genital diaphragm - new critical site for nerve entrapment. Urology 2005; 66:949-952.

4. Sedy J. Sulcus nervi dorsalis penis/clitoridis: Anatomical and clinical implications. Neuroanatomy 2007; 8:58-62.

5. Sedy J. Close proximity of pubic bone and dorsal nerve of penis/clitoris: A pathogenic factor in a sub-group of patients with pudendal nerve entrapment syndrome? Neurourol Urodyn 2007: 27:96.
6. Amarenco G, Lanoe Y, Perrigot M, Goudal H. A new canal syndrome: Compression of the pudendal nerve in Alcock's canal or perinal paralysis of cyclists. Presse Med 1987; 16:399.

7. Nanka O, Sedy J, Jarolím L. Sulcus nervi dorsalis penis: Site of origin of Alcock's syndrome in bicycle riders? Med Hypotheses 2007; 69:1040-1045.

8. Goodson JD. Pudendal neuritis from biking. N Engl J Med 1981; 304:365. 


\section{In Response}

We thank Dr. Šedý for the comments. We agree that pudendal nerve entrapment syndrome can also be caused by the entrapment of the dorsal nerve of the penis/clitoris under the pubis. We are well aware of Dr. Šedý's excellent work in this field and we did include his work in a book chapter on pudendal neuralgia recently authored by us. However, we would like to highlight the philosophical difference between the term pudendal neuropathy and pudendal neuralgia. The former term is often used by perineologists (perineology is a neologism which means the study of the perineum) (1) and encompasses a spectrum of clinical presentations suggestive of pudendal nerve dysfunction (hyperesthesia or hypoesthesia in the perineum) and the confirmatory test is an increase in pudendal nerve terminal motor latencies (PNTML) (2). For the pain physician, the spectrum of patients referred to them are those presenting with pain in the region innervated by pudendal nerve (pudendal neuralgia). The former represents the loss of function of the nerve, which is usually preserved in the latter.

With these 2 terms in mind, our understanding is that the symptoms produced by the compression of dorsal nerve of penis/clitoris against the lower border of the pubic bone results in loss of function of the nerve, such as genital numbness and erectile dysfunction (3). This also reflects your group opinion as quoted in the abstract "....Alcock's syndrome in bicycle riders has been characterized as a prolonged glans and penile insensitivity, genital numbness and an erectile dysfunction." (4). Although we have not developed the ultrasound technique to block the dorsal nerve of the penis/clitoris, the patients affected by compression of this nerve will unlikely be offered a nerve block to produce numbness in the hypoesthetic area. Thus, in our review article focusing on the nerve block technique and pudendal neuralgia, we did not include your work.

\author{
Philip Peng, MBBS FRCPC \\ Director \\ Anesthesia Chronic Pain Program \\ University Health Network \\ Mount Sinai Hospital \\ Director of Research \\ Wasser Pain Management Center \\ Toronto, Ontario Canada \\ E-mail: Philip.Peng@uhn.on.ca
}

\section{References}

1. Beco J, Mouchel J. Understanding the concept of perineology. Int Urogynecol J Pelvic Floor Dysfunct 2002; 13:275277.

2. Beco J. Pudendal neuropathy. One of the main "defects" in perineology. Availabel at: www.perineology.com/files/ 4 beco-athens2006.pdf

3. Leibovitcha I, Morb Y. The vicious cycling: Bicycling related urogenital disor- ders. Eur Urol 2005; 47:277-287.

4. Nanka O, Sedy J, Jarolím L. Sulcus nervi dorsalis penis: Site of origin of Alcock's syndrome in bicycle riders? Med Hypotheses 2007; 69:1040-1045. 